University of Nebraska - Lincoln

DigitalCommons@University of Nebraska - Lincoln

Publications, Agencies and Staff of the U.S.

Department of Commerce

U.S. Department of Commerce

2009

\title{
A fish of many scales: extrapolating sublethal pesticide exposures to the productivity of wild salmon populations
}

David H. Baldwin

NOAA Fisheries Service, David.Baldwin@noaa.gov

Julann A. Spromberg

NOAA Fisheries Service

Tracy K. Collier

NOAA Fisheries Service

Nathaniel L. Scholz

NOAA Fisheries Service

Follow this and additional works at: https://digitalcommons.unl.edu/usdeptcommercepub

Part of the Environmental Sciences Commons

Baldwin, David H.; Spromberg, Julann A.; Collier, Tracy K.; and Scholz, Nathaniel L., "A fish of many scales: extrapolating sublethal pesticide exposures to the productivity of wild salmon populations" (2009). Publications, Agencies and Staff of the U.S. Department of Commerce. 215.

https://digitalcommons.unl.edu/usdeptcommercepub/215

This Article is brought to you for free and open access by the U.S. Department of Commerce at DigitalCommons@University of Nebraska - Lincoln. It has been accepted for inclusion in Publications, Agencies and Staff of the U.S. Department of Commerce by an authorized administrator of DigitalCommons@University of Nebraska - Lincoln. 


\title{
A fish of many scales: extrapolating sublethal pesticide exposures to the productivity of wild salmon populations
}

\author{
David H. Baldwin, ${ }^{1}$ Julann A. Spromberg, Tracy K. Collier, and Nathaniel L. Scholz \\ NOAA Fisheries Service, Northwest Fisheries Science Center, 2725 Montlake Boulevard East, Seattle, Washington 98112 USA
}

Abstract. For more than a decade, numerous pesticides have been detected in river systems of the western United States that support anadromous species of Pacific salmon and steelhead. Over the same interval, several declining wild salmon populations have been listed as either threatened or endangered under the U.S. Endangered Species Act (ESA). Because pesticides occur in surface waters that provide critical habitat for ESA-listed stocks, they are an ongoing concern for salmon conservation and recovery throughout California and the Pacific Northwest. Because pesticide exposures are typically sublethal, a key question is whether toxicological effects at (or below) the scale of the individual animal ultimately reduce the productivity and recovery potential of wild populations. In this study we evaluate how the sublethal impacts of pesticides on physiology and behavior can reduce the somatic growth of juvenile chinook salmon (Oncorhynchus tshawytscha) and, by extension, subsequent sizedependent survival when animals migrate to the ocean and overwinter in their first year. Our analyses focused on the organophosphate and carbamate classes of insecticides. These neurotoxic chemicals have been widely detected in aquatic environments. They inhibit acetylcholinesterase, an enzyme in the salmon nervous system that regulates neurotransmittermediated signaling at synapses. Based on empirical data, we developed a model that explicitly links sublethal reductions in acetylcholinesterase activity to reductions in feeding behavior, food ration, growth, and size at migration. Individual size was then used to estimate sizedependent survival during migration and transition to the sea. Individual survival estimates were then integrated into a life-history population projection matrix and used to calculate population productivity and growth rate. Our results indicate that short-term (i.e., four-day) exposures that are representative of seasonal pesticide use may be sufficient to reduce the growth and size at ocean entry of juvenile chinook. The consequent reduction in individual survival over successive years reduces the intrinsic productivity (lambda) of a modeled oceantype chinook population. Overall, we show that exposures to common pesticides may place important constraints on the recovery of ESA-listed salmon species, and that simple models can be used to extrapolate toxicological impacts across several scales of biological complexity.

Key words: acetylcholinesterase; behavior; carbamate; feeding; growth; modeling; Oncorhynchus tshawytscha; organophosphate; pesticide; population; salmon.

\section{INTRODUCTION}

The deterioration and loss of freshwater and estuarine habitats have led to the widespread decline and extirpation of Pacific salmonid populations (Oncorhynchus sp.) throughout California and the Pacific Northwest (Nehlsen et al. 1991). Many populations of chinook (O. tshawytscha), coho (O. kisutch), sockeye (O. nerka), and chum salmon (O. keta) and steelhead (O. mykiss) are currently listed as either threatened or endangered under the United States Endangered Species Act (ESA). Major societal efforts to restore salmon habitats are currently underway, with the aim of recovering depressed populations and preventing additional extinctions (Good et al. 2007).

Manuscript received 10 October 2008; accepted 2 March 2009; final version received 3 April 2009. Corresponding Editor: K. Stokesbury.

${ }^{1}$ E-mail: David.Baldwin@noaa.gov
Although numerous forms of habitat degradation have contributed to west coast salmon declines (NRC 1996), the relative importance of pollution as a limiting factor for the recovery of ESA-listed species is still poorly defined. This uncertainty is due in part to conceptual and empirical disconnects between individualbased toxicological effects and biological responses at higher scales. In the context of guiding species recovery, management decisions are typically made at the scale of populations. Resolving issues of scale is a central challenge in ecotoxicology, and it extends beyond salmon to at-risk aquatic populations, communities, and ecosystems worldwide (Eggen et al. 2004, Hinton et al. 2005).

Current-use pesticides represent a large and important class of chemical contaminants in aquatic environments. The term pesticide encompasses a diversity of insecticides, herbicides, fungicides, and other biocides. These are applied to agricultural, commercial, residential, and 
urban landscapes throughout the western United States for the purpose of controlling undesirable biological organisms. They move from their point of application by spray drift, surface runoff, irrigation return flows, and other transport processes to aquatic environments that provide critical habitat for threatened and endangered salmon. Extensive monitoring by the U.S. Geological Survey's National Water Quality Assessment (NAWQA) Program has shown that more than 50 different pesticides and pesticide breakdown products occur in the surface waters of several large western basins. These include the San Joaquin, Sacramento, Willamette, Yakima, and Puget Sound basins (see the USGS Pesticide National Synthesis Project; available online). ${ }^{2}$ For example, surface water monitoring in the Clackamas River drainage (a tributary of Oregon's Willamette River) during runoff events from 2000 to 2005 detected an average of 10 different pesticides in each individual water sample (Carpenter et al. 2008). The Clackamas river system provides freshwater rearing habitat for the threatened Upper Willamette River chinook ESU (evolutionarily significant unit; current species listings in other basins are available online). ${ }^{3}$ Overall, the water quality monitoring data collected to date have shown that imperiled species are exposed to complex mixtures of pesticides across potentially large areas of their freshwater and estuarine ranges.

Several current-use pesticides are known to impair the physiology and behavior of salmon. Among the most acutely toxic are the organophosphate (OP) and carbamate (CB) insecticides that target the salmon nervous system. These chemicals block the activity of acetylcholinesterase (AChE), an enzyme that controls chemical signaling at synapses via the neurotransmitter acetylcholine. The organophosphates are a large class of insecticides that include diazinon, malathion, chlorpyrifos, azinphos-methyl, fonofos, methamidofos, methyl parathion, dichlorvos, and phosmet. Examples of carbamates include carbaryl, carbofuran, methomyl, and aldicarb. Although OPs and CBs both inhibit AChE activity, the OPs bind the enzyme irreversibly (Aldridge and Reiner 1972). As a consequence, recovery from exposure to OPs requires the synthesis of new cholinesterase enzyme, a process that can last up to several weeks (mosquitofish, Gambusia affinis, Chambers et al. 2002; goldfish, Carassius auratus, Ferrari et al. 2004). By contrast, the CBs bind AChE reversibly. Because the CB-AChE bond is reversible and relatively short-lived, fish recover from exposure to $\mathrm{CBs}$ on a timescale of a few hours (Ferrari et al. 2004; cutthroat trout, Oncorhynchus clarkii, Labenia et al. 2006).

The effects of organophosphate and carbamate insecticides on the health of fish have been widely investigated over the past several decades (reviewed by

\footnotetext{
$2\langle$ http://water.usgs.gov/nawqa/pnsp/ $\rangle$

3 〈http://www.nwr.noaa.gov/ESA-Salmon-Listings/>
}

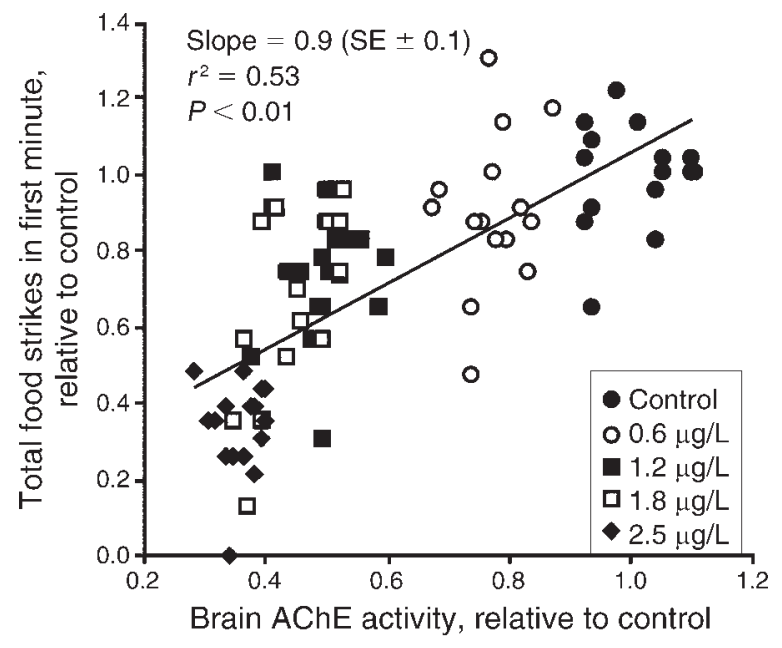

FIG. 1. Reductions in chinook salmon (Oncorhynchus tshawytscha) feeding behavior are correlated with reductions in acetylcholinesterase (AChE) activity induced by the organophosphate insecticide chlorpyrifos. Fish were exposed for $96 \mathrm{~h}$ to a range of chlorpyrifos concentrations between 0 and $2.5 \mu \mathrm{g} / \mathrm{L}$ ( $n=15-17$ fish per exposure concentration). After exposures, feeding behavior and brain AChE activity were measured for each individual fish. Feeding behavior (total food strikes in first minute) was significantly correlated with changes in brain AChE activity (Pearson correlation, $P<0.01$ ). Each point represents the dual measurements from an individual fish and different symbols are used to distinguish the different exposure groups. The data and graph are adapted from Fig. 5B of Sandahl et al. (2005).

Fulton and Key 2001). Because these chemicals interfere with the normal function of the nervous system, numerous studies have focused on fish behavior. For salmonids in particular, anticholinesterase insecticides have been shown to disrupt several behaviors, including swimming (Beauvais et al. 2000, Brewer et al. 2001, Sandahl et al. 2005, Labenia et al. 2006), feeding (Morgan and Kiceniuk 1990, Sandahl et al. 2005), and predator avoidance (Scholz et al. 2000).

Recent work has focused on the OP chlorpyrifos, one of the most commonly detected OPs in NAWQA basins throughout the United States (Hamilton et al. 2004). Chlorpyrifos significantly inhibits AChE in the nervous system and muscle of juvenile steelhead (Sandahl and Jenkins 2002) and coho (Sandahl et al. 2005) at concentrations $<0.5 \mu \mathrm{g} / \mathrm{L}$, or part per billion. These exposure levels are within the upper range of chlorpyrifos detections in salmon habitats (Dubrovsky et al. 1998, Werner et al. 2000). Sublethal inhibition of AChE activity correlates closely to reductions in both swimming behavior and the rate at which juvenile salmon consume prey (Sandahl et al. 2005; Fig. 1). This link between AChE inhibition and behavioral impairment has also been shown for other cholinesterase-inhibiting insecticides, e.g., the effects of diazinon and malathion on AChE activity and swimming behavior in rainbow trout (Beauvais et al. 2000). 

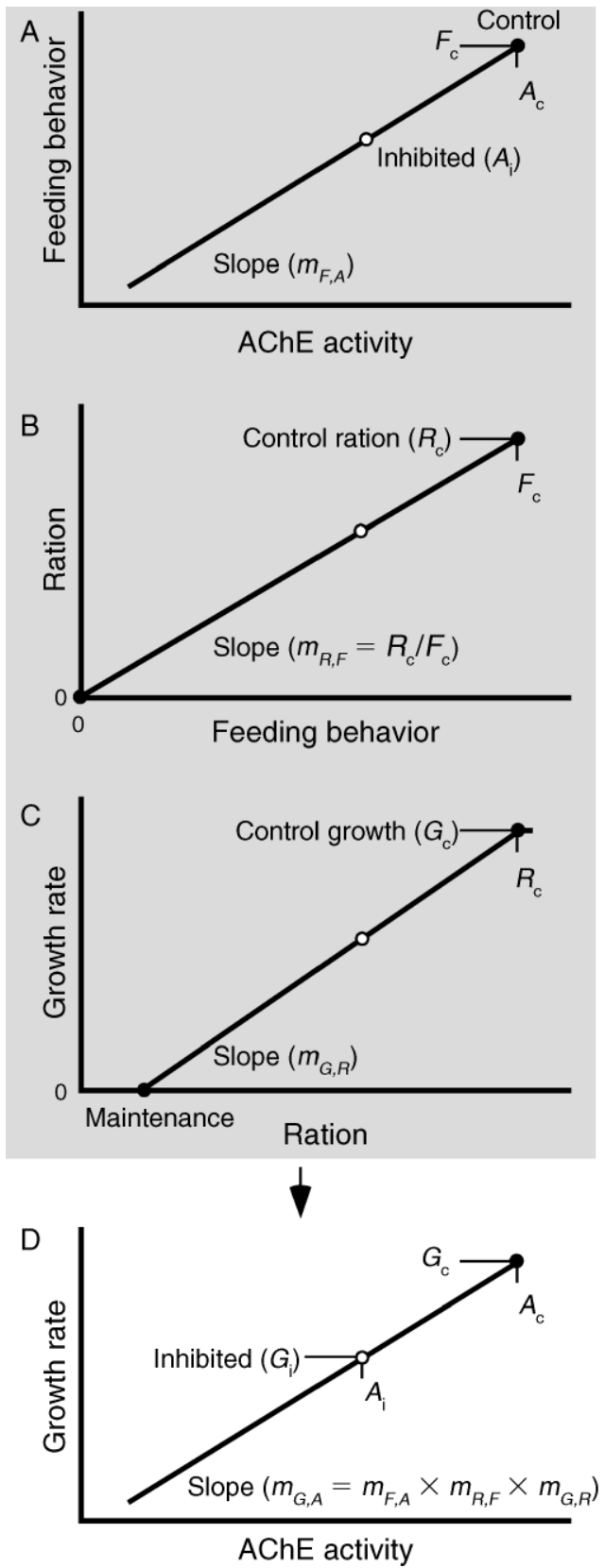
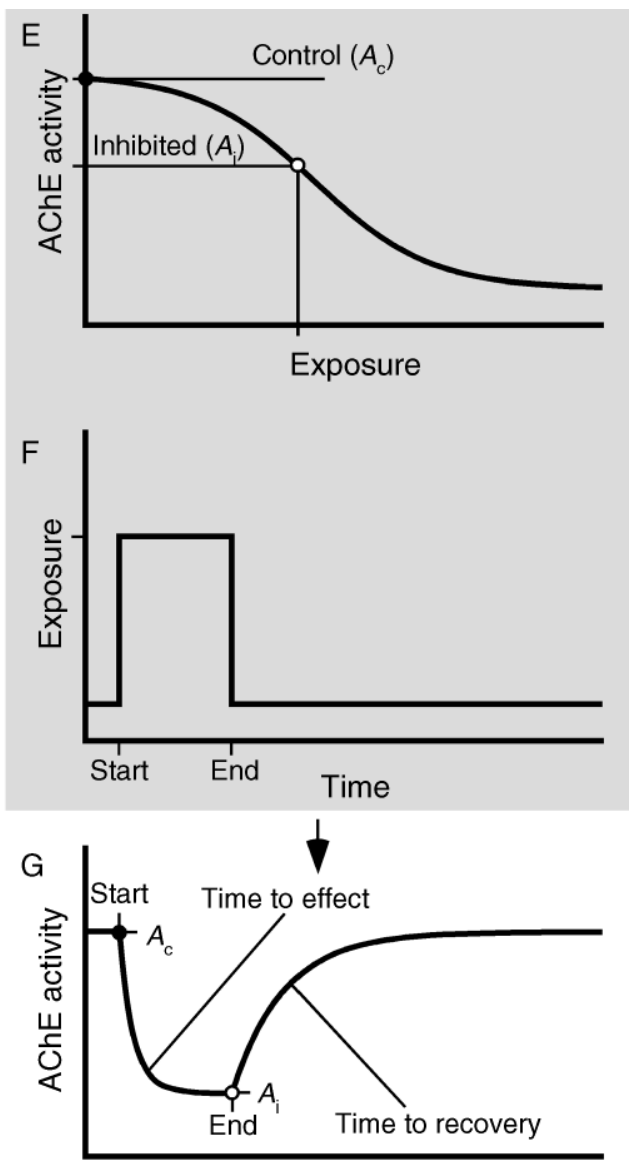

Time

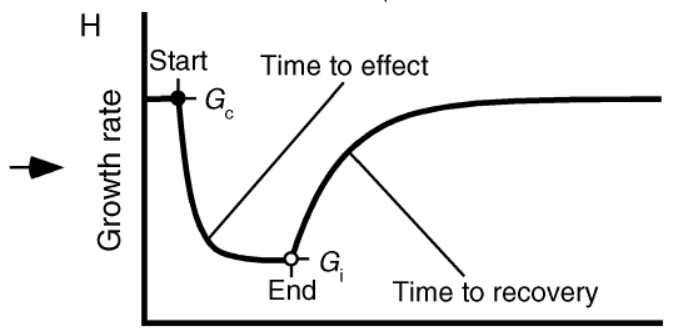

Time

FIG. 2. Relationships used to link anticholinesterase exposure to growth rate. See Methods: Organismal model for details. Relationships in panels A, C, E, and G were all based on empirical data. Solid circles represent control conditions. Open circles (e.g., $\left.A_{\mathrm{i}}\right)$ represent an example of an exposed (inhibited) condition. (A) Linear model relating feeding behavior to acetylcholinesterase activity using a line that passes through the feeding $\left(F_{\mathrm{c}}\right)$ and activity $\left(A_{\mathrm{c}}\right)$ control conditions with a slope of $m_{\mathrm{F}, \mathrm{A}}$. (B) The relationship between food ration and feeding behavior used a line passing through the control conditions and through the origin producing a slope $\left(m_{\mathrm{R}, \mathrm{F}}\right)$ equal to $R_{\mathrm{c}} / F_{\mathrm{c}}$. (C) A linear model was used to relate growth rate to ration using a line passing through the control conditions and through the maintenance condition with a slope denoted by $m_{\mathrm{G}, \mathrm{R}}$. (D) Combining the linear models in panels $\mathrm{A}-\mathrm{C}$ produced a new linear model that relates growth rate to acetylcholinesterase activity and passes through the control conditions $\left(A_{\mathrm{c}}, G_{\mathrm{c}}\right)$ with a slope of $m_{\mathrm{F}, \mathrm{A}}$. (E) Relationship between steady-state acetylcholinesterase activity and exposure concentration showing a dose-dependent reduction. (F) Representation of a constant level of anticholinesterase pesticide exposure (either a single compound or mixtures) over time. $(\mathrm{G})$ The modeled time course of acetylcholinesterase inhibition based on the results from panels $\mathrm{E}$ and $\mathrm{F}$ and by modeling the time to effect and time to recovery as single exponential. (H) Time course for effect of exposure to anticholinesterase on growth rate produced by combining panels D and $\mathrm{G}$. This temporal profile of growth rate was then applied to model the consequences of exposure on the long-term mass gain of the animal. 
One obvious possible consequence of reduced swimming and feeding is a reduction in food uptake and, by extension, subsequent somatic growth of juvenile salmon rearing in freshwater stream systems, lakes, and estuaries contaminated with pesticides. Juvenile growth is a critical determinant of freshwater and marine survival for salmon (Higgs et al. 1995). In chinook, for example, reductions in the somatic growth rate of fry and smolts lead to an increase in sizedependent mortality (Healey 1982, West and Larkin 1987). In an analysis of $>54000$ tagged fish, Zabel and Achord (2004) observed strong size-dependent survival for juvenile chinook during the freshwater phase of their outmigration. Smaller salmon are also more susceptible to predation during their first year in the marine environment (Healey 1982, Holtby et al. 1990, Beamish and Mahnken 2001). Therefore, pesticide exposures that reduce salmon growth may reduce individual survival and, by extension, the recovery potential for ESA-listed populations.

In the present study we use a modeling approach to link short-term, sublethal exposures to $\mathrm{OP}$ and $\mathrm{CB}$ insecticides at the scale of individual animals to the dynamics of an ocean-type chinook salmon population. Whereas stream-type chinook overwinter in fresh water and migrate to the ocean as yearlings, ocean-type chinook migrate as subyearlings several months after hatching and emergence (Groot and Margolis 1991). Because ocean-type chinook move seaward at a relatively small size, feeding and growth in freshwater habitats is particularly important for their first-year survival. The ESA-listed population segments that primarily express ocean-type characteristics include the Lower Columbia Fall, Snake River Fall, Upper Willamette, Puget Sound, Central Valley, and California Coastal chinook evolutionarily significant units (see footnote 3).

Our analysis spans a timescale that ranges from several days (for AChE inhibition and recovery) to several months (for juvenile salmon growth) to several decades (for population recovery). We explore several exposure scenarios designed to reflect the transport of pesticides to salmon habitats via drift, surface runoff, and irrigation return flows. These include single and multiple exposures to $\mathrm{OP}$ and $\mathrm{CB}$ pulses as well as a longer-term OP exposure. The models are based on available empirical data. These are drawn from controlled laboratory studies of pesticide exposure, AChE inhibition and recovery, feeding behavior and ration, and juvenile growth, as well as field studies linking relative size at migration to survival. The models highlight important differences in the population-scale impacts of OPs and CBs that are attributable to differences in the rates at which juvenile chinook recover brain enzyme function. Finally, the model outputs show how yearly pesticide applications in salmon-supporting watersheds may constrain the recovery trajectory of depressed populations.

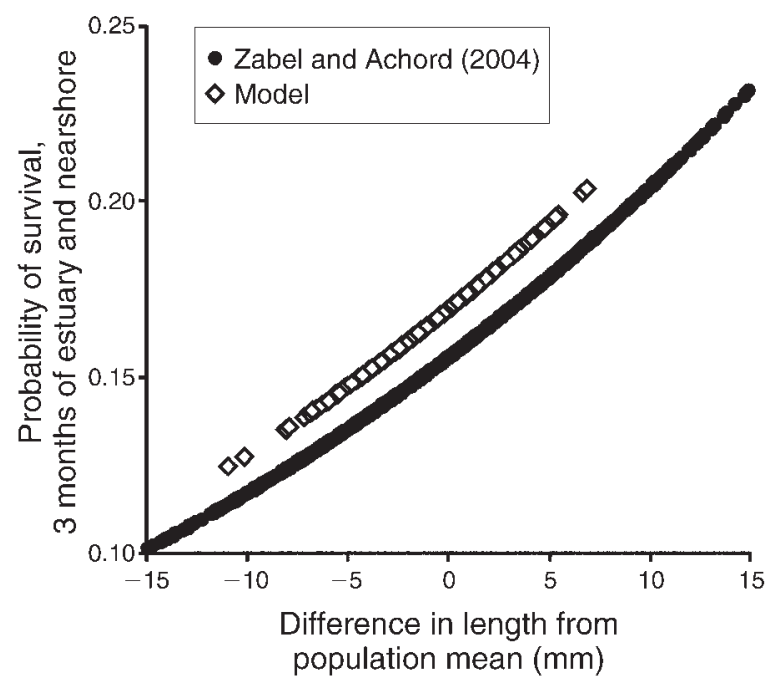

FIG. 3. Relationships between difference in length from the salmon population mean length and probability of survival for a three-month period. Values shown are output based upon the original size and survival equations derived by Zabel and Achord (2004) and equations adapted for the model population used in this paper.

\section{Methods \\ Organismal model}

The connection between AChE activity and the somatic growth of subyearling chinook was developed using a series of linear relationships linking brain enzyme activity to feeding behavior, feeding behavior to food uptake (or ration), and ration to daily somatic growth rate. This is shown schematically in Fig. 2 (panels A-D). The close empirical relationship between AChE activity and the feeding behavior of juvenile salmon (Fig. 2A) has been published previously (Sandahl et al. 2005). Feeding behavior was assumed to be directly proportional to the capture and uptake of prey, which we define as ration (Fig. 2B). Next, an established association between feeding rate and salmon growth (Weatherley and Gill 1995) was used to define the relationship between ration and daily somatic growth rate (Fig. 2C). While this may be influenced by temperature (Brett et al. 1969), our analysis did not incorporate temperature as a variable. Also, while the influence of ration on growth is more complex than considered in the present analysis (e.g., somatic growth rate plateaus as ration approaches an uptake limit), the relationship is reasonably linear at intermediate feeding rates (e.g., Brett et al. 1969). We therefore assumed linearity for animals ingesting prey at intermediate rates that are representative of animals feeding under natural conditions. These collective relationships (Fig. 2A-C) were then combined to calculate daily somatic growth rate as a function of brain AChE activity (Fig. 2D).

The time course relating pesticide exposure to $\mathrm{AChE}$ inhibition and recovery was constructed as shown in Fig. 2E-G. A steady-state dose-response relationship 
TABLE 1. List of values used for control parameters to model organismal growth in wild salmon populations in the western United States.

\begin{tabular}{|c|c|c|c|}
\hline Parameter & Value† & Errort & Sensitivity \\
\hline Acetylcholinesterase activity $\left(A_{\mathrm{c}}\right)$ & 1 (other values relative to control) & $0.06 థ$ & -0.4 \\
\hline Feeding $\left(F_{\mathrm{c}}\right)$ & 1 (other values relative to control) & $0.05 \uparrow$ & 0.2 \\
\hline Ration $\left(R_{\mathrm{c}}\right)$ & $5 \%$ mass $/ \mathrm{d} \#$ & $0.05 \|$ & -0.2 \\
\hline Growth $\left(G_{\mathrm{c}}\right)$ & $1.3 \% \mathrm{mass} / \mathrm{d} \#$ & $0.06 \#$ & 2.3 \\
\hline Feeding vs. activity slope $\left(m_{\mathrm{F}, \mathrm{A}}\right)$ & $1 \uparrow$ & $0.1 \uparrow$ & -0.2 \\
\hline Ration vs. feeding slope $\left(m_{\mathrm{R}, \mathrm{F}}\right)$ & $5\left(R_{\mathrm{c}} / F_{\mathrm{c}}\right)$ & $\mathrm{n} / \mathrm{a}$ & $\mathrm{n} / \mathrm{a}$ \\
\hline Growth vs. ration slope $\left(m_{\mathrm{G}, \mathrm{R}}\right)$ & $0.35 \#$ & $0.02 \#$ & -0.2 \\
\hline Growth vs. activity slope $\left(m_{\mathrm{G}, \mathrm{A}}\right)$ & $1.75\left(m_{\mathrm{F}, \mathrm{A}} \times m_{\mathrm{R}, \mathrm{F}} \times m_{\mathrm{G}, \mathrm{R}}\right)$ & $\mathrm{n} / \mathrm{a}$ & $\mathrm{n} / \mathrm{a}$ \\
\hline Initial mass & $1 \mathrm{~g} \dagger \dagger$ & $0.1 \dagger \dagger$ & 1.0 \\
\hline
\end{tabular}

$\uparrow$ Mean value of a normal distribution used in the model.

I Standard deviation of the normal distribution used in the model.

$\S$ Mean sensitivity when baseline parameter is changed over range of 0.5 to twofold.

- Derived from Sandahl et al. (2005).

\# Derived from Brett et al. (1969).

II Data from Brett et al. (1969) have no variability (ration was the independent variable) so a variability of $1 \%$ was selected to introduce some variability.

$\dagger+$ Consistent with field-collected data for juvenile chinook (Nelson et al. 2004).

(Fig. 2E) was assumed. Dose-response information was not incorporated because the model did not consider exposure to specific pesticides. Note that AChE inhibition in response to "exposure" connotes exposure to either a single anticholinesterase insecticide or a mixture of OPs and CBs. The time course for the exposure was represented as a simple step-shaped pulse with a defined beginning and end (Fig. 2F). The inhibition and recovery of chinook brain AChE activity was modeled using two single-order exponential functions (i.e., with the general form $e^{-k t}$, where $k$ is the decay constant): one for the time required for the exposure to reach full effect and the other for the time required for complete recovery following the end of the exposure (time to effect and time to recovery, respectively; Fig. 2G). This allowed for simulation of differences in toxicokinetics (e.g., rates of uptake and detoxification) for pesticides that bind AChE irreversibly (OPs) and reversibly (CBs). The shape of each calculated exponential function was expressed by its corresponding half-life (equal to $\ln (2) / k)$.

To estimate how subyearling chinook somatic growth will change over time in response to AChE inhibition and recovery, projections for growth as a function of brain enzyme activity (Fig. 2D) were combined with projections for enzyme activity in response to pesticide exposure (Fig. 2G) to determine changes in individual growth rate and size over time (Fig. $2 \mathrm{H}$ ). The individualbased growth model assumed that the time-to-effect and time-to-recovery trajectories for $\mathrm{AChE}$ activity and feeding behavior are equivalent.

The individual-based model was run for 3000 salmon. The population had a normal distribution of initial masses that averaged $1.0 \mathrm{~g}$ with a standard deviation of $0.1 \mathrm{~g}$. This approximates the sizes of ocean-type juvenile chinook in the spring (e.g., Nelson et al. 2004), prior to the onset of most intensive pesticide applications in the spring and summer of each year. Each iteration of the model lasted one day, and the somatic growth rate was calculated for each fish by selecting the parameter values from normal distributions with specified means and standard deviations. This modeled the day-to-day variation in the feeding and growth of individual fish. The mass for each fish was then adjusted based on the calculated growth rate to generate a new mass, and the model was run again. This was repeated for 140 days to approximate the time ocean-type chinook salmon feed in freshwater before they enter an estuary (Myers et al. 2006).

The parameter values defining the control conditions for unexposed animals are listed in Table 1, and those defining each of the different pesticide exposure scenarios are listed in Table 2. The organismal model incorporated exposure as the magnitude of the reduction in AChE activity. Although not within the scope of this study, this would allow the model to be applied to specific anticholinesterase pesticides in salmon habitats (individually or in mixtures), as long as the exposure concentrations, the dose-response relationships, and the time course for AChE inhibition and recovery are known. In the present study, the time to effect for both $\mathrm{OP}$ and $\mathrm{CB}$ insecticides was assumed to be within a few days (Ferrari et al. 2004). As noted earlier, a key difference between OPs and CBs is the time to recovery. Fish exposed to OPs require weeks to recover AChE activity (Chambers et al. 2002, Ferrari et al. 2004) while fish exposed to CBs require only hours to a few days for recovery (e.g., Ferrari et al. 2004, Labenia et al. 2006). As indicated in Table 2, this difference in time to recovery between $\mathrm{OP}$ and $\mathrm{CB}$ pesticides was a focus for the modeling scenarios. We also explored the influence of exposure duration. This included a single pulse lasting four days, four pulses each lasting four days, and a continuous exposure at relatively low concentrations (10\% AChE inhibition) spanning the entire 140-day period of subyearling growth. These scenarios capture the episodic inputs of pesticides into some salmon 
TABLE 2. Values used for each exposure scenario to model organismal growth of salmon exposed to different insecticide treatments.

\begin{tabular}{lccccc}
\hline \hline Scenario & $\begin{array}{c}\text { Exposure start } \\
\text { (d) }\end{array}$ & $\begin{array}{c}\text { Exposure end } \\
\text { (d) }\end{array}$ & $\begin{array}{c}\text { Acetylcholinesterase } \\
\text { activity relative to control } \\
\text { during exposure }\left(A_{\mathrm{i}}\right)\end{array}$ & $\begin{array}{c}\text { Time to effect } \\
\text { (half-life, d) }\end{array}$ & $\begin{array}{c}\text { Time for recovery } \\
\text { (half-life, d) }\end{array}$ \\
\hline OP pulse & 30 & 34 & $0.5(50 \%$ reduction) & 0.5 & 26 \\
OP continuous & 30 & 135 & 0.9 (10\% reduction) & 0.5 & 26 \\
CB pulse & 30 & 34 & 0.5 & 0.5 & 0.5 \\
CB four pulses & 30 & 34 & 0.5 & 0.5 & 0.5 \\
& 40 & 44 & 0.5 & 0.5 & 0.5 \\
& 50 & 64 & 0.5 & 0.5 & 0.5 \\
\hline
\end{tabular}

Note: OP denotes an organophosphate, and CB denotes a carbamate insecticide.

habitats (e.g., via runoff or spray drift) as well as more continuous inputs (e.g., via irrigation return flows).

The outputs of the individual-based model consisted of mean masses (with standard deviations) at the end of the simulated 140-day freshwater growth interval. The model was constructed and run using LabVIEW 7.1 (National Instruments, Austin, Texas, USA). A sensitivity analysis (see Methods: Sensitivity analyses) was performed to determine the relative influence of the different parameter values on the modeled results.

\section{Population model}

The distributions of individual masses for salmon from each of the modeled pesticide exposure groups were used to estimate the size-dependent survival rates for subyearling ocean-type chinook as they transition to the estuary and nearshore marine environment. This was then incorporated into a matrix population model to determine how aggregate reductions in the size of individual animals impact the growth rate and abundance of the larger population. The first-year survival element of the transition matrix incorporated a sizedependent survival rate for a three-month interval encompassing the time subyearling chinook smolts spend in the estuary and nearshore habitats. The mass distributions from the organismal model were converted to length distributions by applying condition factors from data recently collected from outmigrating juvenile salmon in the lower Columbia River and estuary (Johnson et al. 2007). Fish masses (g) were converted to lengths $(\mathrm{mm})$ using the equation, length $=10 \times$ $(\text { mass } / 0.0115)^{1 / 3}$. An empirical relationship between the length of outmigrating juvenile salmon and their survival during migration along the Columbia River has been published previously (Zabel and Achord 2004; Fig. 3). This relationship was adapted to an ocean-type life history by setting survival at the mean size to the three-month survival rate for the control (unexposed) model population (Howell et al. 1985, Kostow 1995, Myers et al. 2006). This reflects an assumption that the relationship between size and survival is equivalent for stream- and ocean-type life histories. Note that the upward shift in the modeled distribution in Fig. 3 is due to the fact that ocean-type chinook from the Willamette basin in Oregon have a higher mean survival rate than the stream-type chinook that were the focus of the study by Zabel and Achord (2004). As shown in Fig. 3, the probability that an individual animal will survive in the estuary is expressed as the length of that animal relative to the mean length of all of the subyearling chinook in the habitat. The relative difference in length was calculated using Eq. 1, and the consequence of this for estuary survival using Eq. 2:

$$
\begin{aligned}
& \Delta \text { length }=\text { fish length }(\mathrm{mm})-\text { mean length }(\mathrm{mm}) \\
& \text { survival }=\frac{\exp [-1.99+(0.0329 \times \Delta \text { length })]}{1+\exp [-1.99+(0.0329 \times \Delta \text { length })]} .
\end{aligned}
$$

Randomly selecting length values from the normal distribution calculated from the individual-based model output and applying Eqs. 1 and 2 generated an estuary survival probability for each fish. This process was replicated 10000 times for each pesticide exposure scenario. For the control (unexposed) population, this produced an estimated mean estuary survival rate of 0.170. Estuary survival rates for the control and pesticide-exposed populations were incorporated in the calculation of first-year survival in the transition matrices.

Projection matrices integrating age-specific survival and reproductive demographic rates were used to determine the population-scale consequences of reduced individual growth and survival. An age-structured lifehistory matrix model for ocean-type chinook salmon with a maximum age of five years was adapted from a model published by Spromberg and Meador (2005). A prospective analysis of the transition matrix A (Caswell 2001) explored the intrinsic population growth rate as a function of the vital rates. The intrinsic population growth rate, $\lambda$, equals the dominant eigenvalue of $\mathbf{A}$ and was calculated using matrix analysis software (MATLAB version 6.5.0; MathWorks, Natick, Massachusetts, USA). The stable age distribution, which describes the proportional number of individuals among the different ages when the population is at equilibrium, was calculated as the right normalized eigenvector corresponding to the dominant eigenvalue $\lambda$. 
TABLE 3. Matrix transition element, sensitivity, and elasticity values for the ocean-type chinook salmon life-history matrix.

\begin{tabular}{cccc}
\hline \hline $\begin{array}{c}\text { Transition } \\
\text { element }\end{array}$ & Value & Sensitivity & Elasticity \\
\hline S1 & 0.00563 & 57.1 & 0.2923 \\
S2 & 0.48 & 0.67 & 0.2923 \\
S3 & 0.246 & 0.48 & 0.1064 \\
S4 & 0.136 & 0.14 & 0.0168 \\
R3 & 314 & 0.0007 & 0.1858 \\
R4 & 677 & 0.0001 & 0.0896 \\
R5 & 1028 & 0.0000 & 0.0168
\end{tabular}

Notes: Control values are listed by the transition element with survival (S) and reproductive contribution (R) for each age class. Numbers following $\mathrm{S}$ and $\mathrm{R}$ refer to age in years. Sensitivity and elasticity were calculated from the transition matrix with control parameters.

A life-history model was constructed for ocean-type chinook with a maximum female age of five years and reproductive maturity at ages 3,4 , or 5 years. Oceantype chinook migrate from their natal stream within several months of hatching and spend several months rearing in estuary and nearshore habitats before moving to the open ocean. Transition values were determined from published demographic data describing the survival and reproductive characteristics of several ocean-type chinook populations (Healey and Heard 1984, Howell et al. 1985, Roni and Quinn 1995, Ratner et al. 1997, PSCCTC 2002, Greene and Beechie 2004). The sex ratio of spawners was approximately $1: 1$. Estimates of sizebased mean fecundities (with SD in parentheses) for ages 3,4 , and 5 years of 4511 (65), 5184 (89), and 5812 (102) were drawn from Howell et al. (1985) using lengthfecundity relationships from Healey and Heard (1984). Control matrix values for the chinook model are listed in Table 3.

The control (unexposed) scenario produced a modeled population with an increasing growth rate. All population characteristics exhibit density-independent dynamics. The simple model also assumed a closed system with no net change in population abundance due to migration to, or straying from, other chinook populations. No stochastic impacts were included beyond natural variability, and this was represented with parameter values selected once each iteration (year) from a normal distribution about a mean. Ocean conditions, freshwater habitat quality (other than pesticide exposures), fishing pressure, and resource availability were assumed constant and density independent.

The population abundance projections were run for 20 years in one-year time steps with initial conditions that included 500000 individuals across a stable age distribution as determined from the control matrix. This produced an initial spawning population of 895 adults aged 3, 4, and 5 years. The model recalculated first-year survival each year using the three-month estuary survival value selected from a normal distribution with the mean and standard deviation produced by each pesticide exposure scenario (Table 4). Population model output consisted of the annual number of returning spawners, excluding jacks (in this model, males that return before age 3). Five thousand repetitions of the model projections allowed the calculation of the mean spawner abundance, standard deviation, and 95\% confidence intervals for each exposure scenario.

\section{Sensitivity analyses}

A sensitivity analysis was conducted on the organismal model by calculating changes in final mass due to 0.5 to twofold changes in model parameters. The analysis revealed that changes in the modeled growth rate of unexposed chinook ( $G_{\mathrm{c}}$ in Fig. 2 and Table 1$)$ had the greatest influence on the final estimated masses (Table 1). A $10 \%$ increase in $G_{\mathrm{c}}$, for example, would produce a $23 \%$ increase in final mass. Although this parameter value was experimentally derived for sockeye salmon (Brett et al. 1969), it is within the reported range for other species of salmonids (reviewed in Weatherley and Gill 1995). Changes to the initial mass of the fish also had a direct influence on the final size. Large changes (i.e., 0.5 to twofold) in the other key parameters listed in Table 1 produced relatively small proportional changes in the final projected mass of subyearling chinook. The variability in the final mass was largely due to the variability in initial mass (data not shown), because the other parameters (e.g., $G_{\mathrm{c}}$ ) fluctuated daily around their means.

The influence of each population matrix element, $a_{i j}$, on $\lambda$ was assessed by calculating the sensitivity values for the transition matrix A. The sensitivity of matrix element $a_{i j}$ equals the rate of change in $\lambda$ with respect

TABLE 4. Organismal and population model outputs for each scenario examined.

\begin{tabular}{|c|c|c|c|c|c|c|}
\hline \multirow[b]{2}{*}{ Scenario } & \multicolumn{2}{|c|}{ Organismal model (after 140 days) } & \multicolumn{4}{|c|}{ Population model (after 20 years) } \\
\hline & $\begin{array}{c}\text { Mass } \\
(\mathrm{g})\end{array}$ & $\begin{array}{l}\text { Length } \\
(\mathrm{mm})\end{array}$ & $\begin{array}{c}\text { Calculated estuary } \\
\text { survival }\end{array}$ & $\lambda$ & $\begin{array}{l}\text { Spawner abundance } \\
\text { (\% of control) }\end{array}$ & $\begin{array}{c}\text { Spawner increase } \\
(\%)\end{array}$ \\
\hline Control & $6.1(0.6)$ & $80.9(2.7)$ & $0.170(0.012)$ & 1.10 & 100 & 523 \\
\hline OP pulse & $4.4(0.4)$ & $72.4(2.5)$ & $0.134(0.010)$ & 1.03 & 27.0 & 68 \\
\hline OP continuous & $5.1(0.5)$ & $76.0(2.6)$ & $0.148(0.011)$ & 1.06 & 47.3 & 195 \\
\hline CB pulse & $5.9(0.6)$ & $79.8(2.8)$ & $0.165(0.013)$ & 1.09 & 85.6 & 433 \\
\hline $\mathrm{CB}$ four pulses & $5.3(0.5)$ & $77.1(2.7)$ & $0.153(0.012)$ & 1.07 & 56.4 & 251 \\
\hline
\end{tabular}

Notes: See Table 2 for definition of the scenarios. The intrinsic population growth rate is $\lambda$. Values in parentheses following means are standard deviations. 

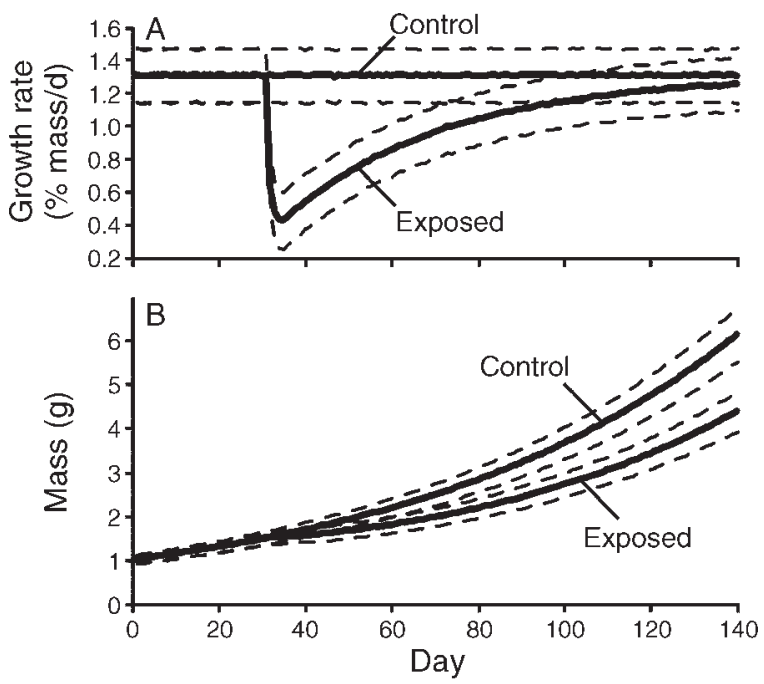

FIG. 4. Representative outputs from the organismal model. (A) Somatic growth rate over time for two populations of 3000 fish. The plot shows the mean (solid line) and \pm SD (dashed lines) for the somatic growth rate as determined by the model. The exposed fish show the impact of a four-day exposure starting on day 30 (a 50\% AChE inhibition with a time-torecovery half-life of 26 days). (B) Mass over time for the same populations of fish as shown in (A) using a starting mass of $1 \mathrm{~g}$. After 140 days the exposed fish weighed $72 \%$ of the unexposed fish.

to $a_{i j}$, defined by $\delta \lambda / \delta a_{i j}$. Parameter values and their corresponding sensitivity values are listed in Table 3. A sensitivity analysis of the matrix for the unexposed population of fish revealed that population growth rate $(\lambda)$ is most strongly influenced by changes in first-year survival. The elasticity analysis of the unexposed (control) matrix indicated that changes to the firstand second-year survival rates would have the greatest per unit effect on $\lambda$, and that age 3 reproductive output contributed the most to $\lambda$ under control conditions with gradually lesser contributions from ages 4 and 5 due to the lower proportions of age 4 and 5 spawners (Table 3 ). Because first-year survival changes in each model run, 0.5 to twofold changes in first-year survival were incorporated and sensitivity and elasticity values recalculated. Slight changes occurred in the sensitivity and elasticity values, but the general trends across parameter values were not altered (Table 3 ).

\section{Results}

\section{Pesticide impacts on individual animals}

Individual-based and population model outputs for all pesticide exposure scenarios are shown in Table 4. A more detailed example of two outputs of the individualbased model is shown in Fig. 4. The time course of the somatic growth rates of control and OP pulse-exposed fish is depicted in Fig. 4A. From this output, the mass of each fish over time was calculated (Fig. 4B). The final mean mass of the control fish is consistent with masses observed in subyearling salmon collected from the
Columbia River estuary (Johnson et al. 2007). The reduced final mean mass of the OP-exposed fish reflects the reduced growth during the OP pulse exposure and the prolonged recovery period. The masses were converted to lengths and translated into three-month estuary survival rates for use in the population model (Table 4). Relative to the control population, all of the exposure scenarios showed lower mean masses and, therefore, survival rates. Of the different pesticide exposure scenarios modeled, the single OP pulse produced the largest reduction in survival. Conversely, exposure to a single $\mathrm{CB}$ pulse produced the smallest reduction (Table 4).

\section{Pesticide impacts on chinook populations}

The survival rates computed for each scenario by the individual-based model were used to parameterize the population model. The model was then run and outputs were used to assess potential changes in productivity due to changes in population growth rate $(\lambda)$. The estimated $\lambda$ for the unexposed population was 1.10 (Table 4), a rate consistent with field observations (Kareiva et al. 2000). By comparison, the growth rate of the chinook population with the subyearling class exposed each year to a single OP pulse was lower $(\lambda=1.03)$ although still increasing. A notable finding is that modest, pesticideinduced reductions in $\lambda$ produced a large reduction in the productivity of a modeled chinook population over time (Fig. 5). Exposure to a single OP pulse caused the largest reduction in population growth, followed by a continuous OP exposure (10\% inhibition) and multiple exposures to $\mathrm{CB}$ insecticides (Table 4). The single CB pulse scenario slightly decreased the population growth

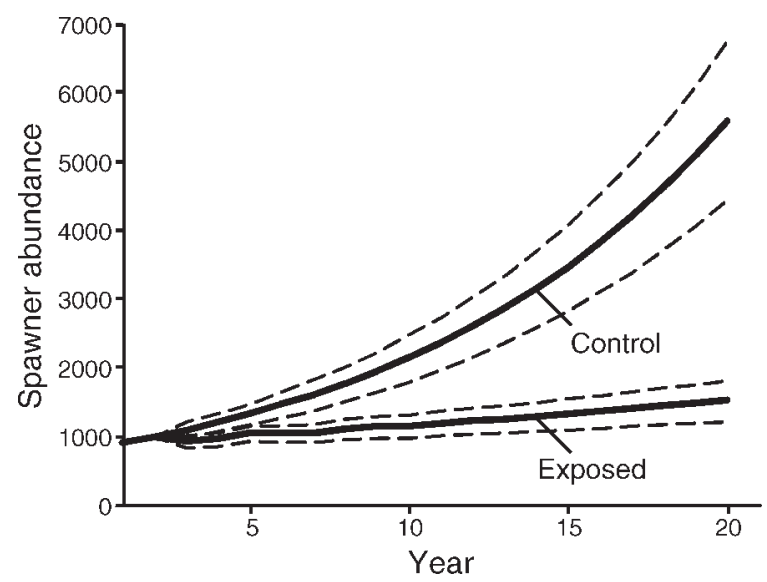

FIG. 5. Mean spawner abundance $(95 \%$ CI indicated by dashed lines) over a 20 -year projection for the exposed and unexposed populations using size at 140 days from the output in Fig. 4 as input for calculating first-year survival for oceantype chinook salmon. As in Fig. 4, this scenario represents a four-day exposure that produces a $50 \% \mathrm{AChE}$ inhibition with a time-to-recovery half-life of 26 days. After 20 years, the exposed population spawner abundance is $27 \%$ of control spawner abundance. 
rate and spawner abundance, but the 95\% confidence intervals overlap with the control population (output not shown).

While a change in $\lambda$ is likely to be the most meaningful output in terms of estimating impacts on wild salmon populations, we also projected pesticide-induced changes in the number of returning spawners in a modeled chinook population each year of a span of 20 years. The unexposed population (beginning with 895 spawners) increased in adult abundance by 523\%. Projected increases in the number of spawners in the pesticideexposed populations were all comparatively lower (e.g., a $68 \%$ increase for the single OP pulse scenario: Fig. 5, Table 4).

\section{DisCUSSION}

Models incorporating empirical data from both the laboratory and the field were used to link sublethal changes in juvenile salmon brain chemistry to feeding behavior, food ration, growth, and survival. The model outputs showed that a pesticide exposure lasting only a few days can change the freshwater growth trajectory and, by extension, the subsequent survival of subyearling animals. Moreover, the seasonal transport of pesticides to salmon habitats over successive years can slow the recovery of depressed populations. Although the models are simplistic and required several (transparent) assumptions, the magnitude of the responses indicates that common pesticides may significantly limit the conservation and recovery of threatened and endangered stocks in California and the Pacific Northwest.

Our findings add to a growing body of evidence that toxics can limit salmonid populations, and that delayed impacts that occur when animals migrate to the ocean can be particularly influential. Early life stage toxicity caused by dioxin played an important role in the decline of lake trout in Lake Ontario in the 20th century (Cook et al. 2003). Early life stage toxicity caused by exposures to crude oil reduced the subsequent marine survival of pink salmon (Heintz et al. 2000) and likely contributed to the delayed population declines of pink salmon following the 1989 Exxon Valdez oil spill (Peterson et al. 2003). The toxic effects of aluminum (made bioavailable by acid rain and acidified rivers) on juvenile Atlantic salmon from the North Atlantic are also delayed, and primarily manifest when fish transition to the marine environment (Kroglund and Finstad 2003). Dietary exposure to chemical contaminants has also been estimated to significantly reduce the population abundance of outmigrating chinook in the Columbia River Basin due to pathogen exposure and disease-induced mortality during estuary residence (Loge et al. 2005). These studies, together with our results for common current-use pesticides, collectively reinforce the need to consider delayed population effects arising from subtle but important impacts on the health and performance of individual fish (Peterson et al. 2003).
Organophosphate insecticides have a greater projected impact than carbamates, with a four-day OP exposure producing outmigrants that are $\sim 10 \%$ shorter in length. Over 20 years, seasonal exposures to a fourday OP pulse were projected to reduce spawner abundance by $73 \%$ relative to an unexposed control population. The effects of carbamate exposures on modeled individuals and populations are less severe because the recovery window for brain AChE activity is relatively brief. Nevertheless, all four modeled pesticide exposure scenarios reduced population growth rate and spawner abundance relative to an unexposed chinook population. These population-scale effects are largely attributable to individual survival rates during the critical first year of the ocean-type life history. Our findings are therefore in agreement with other lifehistory models of chinook salmon that have previously concluded that first-year survival is an important determinant of the overall population growth rate (Ratner et al. 1997, Kareiva et al. 2000, Spromberg and Meador 2005).

Our modeled exposure scenarios were intended to capture both episodic and continuous inputs of pesticides into freshwater habitats. Although they oversimplify real-world conditions, they allowed us to assess toxicological responses to exposures that were realistic in terms of both duration and degree of AChE inhibition. Under natural conditions, exposure to pulses of pesticides at a constant level for 96 hours is unlikely. Threatened and endangered chinook traverse some of the most intensively farmed watersheds in California and the Pacific Northwest (e.g., the Central Valley in California and the Willamette Valley in Oregon). Pesticide use across these landscapes can be highly variable in space and time. In addition, there are numerous $\mathrm{OP}$ and $\mathrm{CB}$ insecticides in current use, and these can enter salmon habitats via different transport pathways. Hence, some ocean-type chinook are likely to be exposed to multiple pesticides from multiple sources at multiple points along their freshwater migration route to the ocean. Modeling the full range of this environmental complexity was beyond the scope of the current study.

Our key finding that demographic changes in salmon populations can be quantitatively extrapolated from pesticide effects on individuals is important from the standpoint of comparing the likely efficacy of future habitat restoration activities. Several recent studies have sought to predict how specific ESA-listed populations will respond to various improvements to the physical and biological condition of river systems that support salmon (e.g., Scheuerell et al. 2006). Our modeled populations were not designed to represent a particular chinook population segment, and they did not incorporate potentially influential life-history information that may vary among chinook populations. This includes, for example, density-dependent effects on juvenile growth as well as the effects of adult migration (i.e., straying) on adult spawner abundance. Our results using a more 
simplified and generic model for chinook show how improving water quality conditions by reducing the load of common pollutants could potentially increase population viability and rate of recovery. This should allow resource managers to consider pesticides at the same biological scale as physical and biological stressors when prioritizing habitat restoration activities. Where more refined information is needed, it should also be possible to expand the complexity of our current models to capture the geographic distribution (in relation to agricultural land use) and life-history characteristics of a specific ESU.

As with any model, the analyses conducted for this study have the potential to either overestimate or underestimate actual impacts of $\mathrm{OP}$ and $\mathrm{CB}$ pesticides on salmon survival and population productivity. For example, if short-term exposures to OPs do not inhibit brain AChE activity by 50\%, reductions in survival and population growth will be less than projected by the scenarios presented here (Table 4). Under natural exposure conditions, the degree of AChE inhibition in juvenile salmon will depend on (1) concentrations of OPs and CBs in salmon habitats, (2) the relative toxic potencies of individual pesticides, and (3) possible cooccurrence between a given chemical and other anticholinesterase agents. For example, chlorpyrifos inhibits AChE activity by $50 \%$ at $\sim 1.5$ ppb (96-h exposure; Sandahl et al. 2005), a concentration near the upper end of surface water detections in salmon habitats (Werner et al. 2000). Therefore, a 50\% reduction in AChE activity is more likely when chlorpyrifos co-occurs with other OPs and CBs. Exposure to chlorpyrifos alone may still influence population-scale processes, but this would likely be to a lesser extent than predicted by our single OP pulse scenario. We also assumed the time-torecovery trajectories for brain AChE activity and feeding behavior are equivalent for salmon exposed to OPs. These biochemical and behavior metrics for pesticide toxicity are closely correlated in juvenile salmon (Sandahl et al. 2005), and recovery of AChE activity takes place over a period of weeks in OPexposed fish (Chambers et al. 2002, Ferrari et al. 2004). However, the time course for behavioral recovery has not been experimentally determined. If salmon are somehow able to compensate for depressed enzyme activity, and they begin feeding earlier than assumed in our current analysis, our model outputs will overestimate impacts on juvenile growth.

Conversely, there are several important reasons why our model outputs may underestimate actual impacts on ESA-listed chinook populations. First, our models do not include a food web component. By design, OP and CB insecticides are highly toxic to the terrestrial, riparian, and aquatic insects and crustaceans that juvenile salmon rely on for food. Concentrations that reduce foraging behavior in subyearling salmon are also likely to reduce the diversity and abundance of prey species (e.g., Van den Brink et al. 1996). This will likely exacerbate the direct effects of anticholinesterase pesticides on chinook feeding and growth. These types of food web effects have been shown to reduce the growth of fish (chlorpyrifos; Brazner and Kline 1990) and, more recently, amphibians (malathion; Relyea and Diecks 2008). Second, the toxicity of certain mixtures of OP and $\mathrm{CB}$ chemicals has recently been shown to be at least additive and, in some cases, synergistic (Scholz et al. 2006, Laetz et al. 2009). For example, juvenile coho exposed to a mixture containing the OPs diazinon and malathion show highly depressed brain enzyme activity. The effects of the mixture were significantly greater than expected based on the toxic potencies of the individual chemicals, and fish died at concentrations that would be expected to be sublethal based on a dose-addition model. Thus, insecticides in salmon habitats may interact to produce synergistic AChE inhibition. This is an important consideration because pesticides commonly occur in surface waters as mixtures (Hamilton et al. 2004). Third, the impacts of pesticides on salmon foraging behavior can be expected to occur in parallel with other habitat stressors that affect juvenile growth. This includes, for example, the adverse effects of elevated water temperatures (Marine and Cech 2004; reviewed by Richter and Kolmes 2005). Numerous salmon-bearing stream segments are currently classified as impaired under section 303(d) of the Clean Water Act because of high temperatures (information available online). ${ }^{4}$ Although combinatorial impacts have not been investigated, OP and $\mathrm{CB}$ insecticides could disproportionately limit salmon growth in areas where temperature or other habitat conditions are unfavorable.

In conclusion, our model outputs have shown that environmentally realistic pesticide exposures may limit the recovery potential of ESA-listed salmon populations via delayed reductions in growth and survival. The models relied on empirical data where available. Where data were unavailable, we made simple, transparent assumptions that are verifiable with additional research. We focused our analysis on ocean-type chinook populations, but this approach should also work on other species of salmon that have more complex freshwater life histories. It should also be applicable to different kinds of contaminants (e.g., endocrine disruptors) and other pathways for sublethal toxicity, so long as these ultimately influence individual survival or reproduction. Establishing toxicological linkages across biological scales is necessary to (1) identify which chemicals in salmon habitats should be a priority for toxic reduction strategies; (2) place water quality in the appropriate context for relative risk comparisons with physical and biological forms of habitat degradation; (3) estimate the population-scale benefits of restoration projects that improve water quality; and (4) provide a basis for more sophisticated modeling analyses that focus on specific

\footnotetext{
${ }^{4}\langle$ http://www.epa.gov/owow/tmdl/ $\rangle$
} 
population segments and incorporate indirect effects (e.g., via food webs) and interactions between chemical and nonchemical stressors.

\section{ACKNOWLEDGMENTS}

The authors thank Kate Macneale, Rich Zabel, and Mark Myers for helpful comments on the manuscript. This work was supported by NOAA's Office of Protected Resources and the NOAA Coastal Storms Program.

\section{Literature Cited}

Aldridge, W. N., and E. Reiner. 1972. Enzyme inhibitors as substrates: interactions of esterases with esters of organophosphorus and carbamic acids. North-Holland, Amsterdam, The Netherlands.

Beamish, R. J., and C. Mahnken. 2001. A critical size and period hypothesis to explain natural regulation of salmon abundance and the linkage to climate and climate change. Progress in Oceanography 49:423-437.

Beauvais, S. L., S. B. Jones, S. K. Brewer, and E. E. Little. 2000. Physiological measures of neurotoxicity of diazinon and malathion to larval rainbow trout (Oncorhynchus mykiss) and their correlation with behavioral measures. Environmental Toxicology and Chemistry 19:1875-1880.

Brazner, J. C., and E. R. Kline. 1990. Effects of chlorpyrifos on the diet and growth of larval fathead minnows, Pimephales promelas, in littoral enclosures. Canadian Journal of Fisheries and Aquatic Sciences 47:1157-1165.

Brett, J. R., J. E. Shelbourn, and C. T. Shoop. 1969. Growth rate and body composition of fingerling sockeye salmon, Oncorhynchus nerka, in relation to temperature and ration size. Journal of the Fisheries Board of Canada 26:2363-2394.

Brewer, S. K., E. E. Little, A. J. DeLonay, S. L. Beauvais, S. B. Jones, and M. R. Ellersieck. 2001. Behavioral dysfunctions correlate to altered physiology in rainbow trout (Oncorynchus mykiss) exposed to cholinesterase-inhibiting chemicals. Archives of Environmental Contamination and Toxicology 40:70-76.

Carpenter, K. D., S. Sobieszczyk, A. J. Arnsberg, and F. A. Rinella. 2008. Pesticide occurrence and distribution in the lower Clackamas River basin, Oregon, 2000-2005. U.S. Geological Survey Scientific Investigations Report 20085027.

Caswell, H. 2001. Matrix population models: construction, analysis, and interpretation. Sinauer Associates, Sunderland, Massachusetts, USA.

Chambers, J. E., J. S. Boone, R. L. Carr, H. W. Chambers, and D. L. Straus. 2002. Biomarkers as predictors in health and ecological risk assessment. Human and Ecological Risk Assessment 8:165-176.

Cook, P. M., J. A. Robbins, D. D. Endicott, K. B. Lodge, P. D. Guiney, M. K. Walker, E. W. Zabel, and R. E. Peterson. 2003. Effects of aryl hydrocarbon receptor-mediated early life stage toxicity on lake trout populations in Lake Ontario during the 20th century. Environmental Science and Technology 37:3864-3877.

Dubrovsky, N. M., C. R. Kratzer, L. R. Brown, J. M. Gronberg, and K. R. Burow. 1998. Water quality in the San Joaquin-Tulare basins, California. U.S. Geological Survey Circular 1159.

Eggen, R. I. L., R. Behra, P. Burkhardt-Holm, B. I. Escher, and N. Schweigert. 2004. Challenges in ecotoxicology. Environmental Science and Technology 38:58A-64A.

Ferrari, A., A. Venturino, and A. M. Pechen de D'Angelo. 2004. Time course of brain cholinesterase inhibition and recovery following acute and subacute azinphosmethyl, parathion, and carbaryl exposure in the goldfish (Carassius auratus). Ecotoxicology and Environmental Safety 57:420425 .
Fulton, M. H., and P. B. Key. 2001. Acetylcholinesterase inhibition in estuarine fish and invertebrates as an indicator of organophosphorus insecticide exposure and effects. Environmental Toxicology and Chemistry 20:37-45.

Good, T. P., T. J. Beechie, P. McElhany, M. M. McClure, and M. H. Ruckelshaus. 2007. Recovery planning for endangered species act, listed pacific salmon: using science to inform goals and strategies. Fisheries 32:426-440.

Greene, C. M., and T. J. Beechie. 2004. Consequences of potential density-dependent mechanisms on recovery of ocean-type chinook salmon (Oncorhynchus tshawytscha). Canadian Journal of Fisheries and Aquatic Sciences 61: $590-602$.

Groot, C., and L. Margolis, editors. 1991. Pacific salmon life histories. University of British Columbia Press, Vancouver, British Columbia, Canada.

Hamilton, P. A., T. L. Miller, and D. N. Myers. 2004. Water quality in the nation's streams and aquifers-overview of selected findings, 1991-2001. U.S. Geological Survey Circu$\operatorname{lar} 1265$.

Healey, M. C. 1982. Timing and relative intensity of sizeselective mortality of juvenile chum salmon (Oncorhynchus $k e t a$ ) during early sea life. Canadian Journal of Fisheries and Aquatic Sciences 39:952-957.

Healey, M. C., and W. R. Heard. 1984. Inter- and intrapopulation variation in the fecundity of chinook salmon (Oncoryhchus tshawytscha) and its relevance to life history theory. Canadian Journal of Fisheries and Aquatic Sciences 41:476-483.

Heintz, R. A., S. D. Rice, A. C. Wertheimer, R. F. Bradshaw, F. P. Thrower, J. E. Joyce, and J. W. Short. 2000. Delayed effects on growth and marine survival of pink salmon Oncorhynchus gorbuscha after exposure to crude oil during embryonic development. Marine Ecology Progress Series 208:205-216.

Higgs, D. A., J. S. MacDonald, C. D. Levings, and B. S. Dosanjh. 1995. Nutrition and feeding habits in relation to life history stage. Pages 161-315 in C. Groot, L. Margolis, and W. C. Clarke, editors. Physiological ecology of Pacific salmon. University of British Columbia Press, Vancouver, British Columbia, Canada.

Hinton, D. E., S. W. Kullman, R. C. Hardman, D. C. Volz, P. J. Chen, M. Carney, and D. C. Bencic. 2005. Resolving mechanisms of toxicity while pursuing ecotoxicological relevance? Marine Pollution Bulletin 51:635-648.

Holtby, L. B., B. C. Andersen, and R. K. Kadowak. 1990. Importance of smolt size and early ocean growth to interannual variability in marine survival of coho salmon (Oncorhynchus kisutch). Canadian Journal of Fisheries and Aquatic Sciences 47:2181-2194.

Howell, P., K. Jones, D. Scarnecchia, L. LaVoy, W. Kendra, D. Ortmann, C. Neff, C. Petrosky, and R. Thurow. 1985. Stock assessment of Columbia River anadromous salmonids. Oregon Department of Fish and Wildlife, Fish Research Project DE-AI79-84BP12737, Final Report to Bonneville Power Administration, Portland, Oregon.

Johnson, L. L., G. M. Ylitalo, M. R. Arkoosh, A. N. Kagley, C. L. Stafford, J. L. Bolton, J. Buzitis, B. F. Anulacion, and T. K. Collier. 2007. Contaminant exposure in outmigrant juvenile salmon from Pacific Northwest estuaries. Environmental Monitoring and Assessment 124:167-194.

Kareiva, P., M. Marvier, and M. McClure. 2000. Recovery and management options for spring/summer chinook salmon in the Columbia River basin. Science 290:977-979.

Kostow, K. 1995. Biennial report on the status of wild fish in Oregon. Oregon Department of Fish and Wildlife Report, Portland, Oregon, USA.

Kroglund, F., and B. Finstad. 2003. Low concentrations of inorganic monomeric aluminum impair physiological status and marine survival of Atlantic salmon. Aquaculture 222: 119-133. 
Labenia, J. S., D. H. Baldwin, B. L. French, J. W. Davis, and N. L. Scholz. 2006. Behavioral impairment and increased predation mortality in cutthroat trout exposed to carbaryl. Marine Ecology Progress Series 329:1-11.

Laetz, C. A., D. H. Baldwin, T. K. Collier, V. Hebert, J. D. Stark, and N. L. Scholz. 2009. The synergistic toxicity of pesticide mixtures: implications for risk assessment and the conservation of endangered Pacific salmon. Environmental Health Perspectives 3:348-353.

Loge, F., M. R. Arkoosh, T. R. Ginn, L. L. Johnson, and T. K. Collier. 2005. Impact of environmental stressors on the dynamics of disease transmission. Environmental Science and Technology 39:7329-7336.

Marine, K. R., and J. J. Cech. 2004. Effects of high water temperature on growth, smoltification, and predator avoidance in juvenile Sacramento River chinook salmon. North American Journal of Fisheries Management 24:198-210.

Morgan, M. J., and J. W. Kiceniuk. 1990. Effect of fenitrothion on the foraging behavior of juvenile Atlantic salmon. Environmental Toxicology and Chemistry 9:489-495.

Myers, J., C. Busack, D. Rawding, A. Marshall, D. Teel, D. M. Van Doornik, and M. T. Maher. 2006. Historical population structure of Pacific salmonids in the Willamette River and lower Columbia River basins. U.S. Department of Commerce, National Oceanic and Atmospheric Administration Technical Memorandum NMFS-NWFSC-73.

Nehlsen, W., J. E. Williams, and J. A. Lichatowich. 1991. Pacific salmon at the crossroads: stocks at risk from California, Oregon, Idaho, and Washington. Fisheries 16: 4-21.

Nelson, T. S., G. Ruggerone, H. Kim, R. Schaefer, and M. Boles. 2004. Juvenile chinook migration, growth and habitat use in the Lower Green River, Duwamish River and nearshore of Elliott Bay 2001-2003, draft report. King County Department of Natural Resources and Parks, Seattle, Washington, USA.

NRC (National Research Council). 1996. Upstream: salmon and society in the Pacific Northwest. National Academy Press, Washington, D.C., USA.

Peterson, C. H., S. D. Rice, J. W. Short, D. Esler, J. L. Bodkin, B. E. Ballachey, and D. B. Irons. 2003. Long-term ecosystem response to the Exxon Valdez oil spill. Science 302:20822086.

PSCCTC (Pacific Salmon Commission Chinook Technical Committee). 2002. Pacific Salmon Commission Joint Chinook Technical Committee report: annual exploitation rate analysis and model calibration. Report TCCHINOOK (02)3. Vancouver, British Columbia, Canada.

Ratner, S., R. Lande, and B. B. Roper. 1997. Population viability analysis of spring chinook salmon in the South Umpqua River, Oregon. Conservation Biology 11:879-889.

Relyea, R. A., and N. Diecks. 2008. An unforeseen chain of events: lethal effects of pesticides on frogs at sublethal concentrations. Ecological Applications 18:1728-1742.

Richter, A., and S. A. Kolmes. 2005. Maximum temperature limits for chinook, coho, and chum salmon, and steelhead trout in the Pacific Northwest. Reviews in Fisheries Science 13:23-49.

Roni, P., and T. P. Quinn. 1995. Geographic variation in size and age of North American chinook salmon. North American Journal of Fisheries Management 15:325-345.

Sandahl, J. F., D. H. Baldwin, J. J. Jenkins, and N. L. Scholz. 2005. Comparative thresholds for acetylcholinesterase inhibition and behavioral impairment in coho salmon exposed to chlorpyrifos. Environmental Toxicology and Chemistry 24: $136-145$.

Sandahl, J. F., and J. J. Jenkins. 2002. Pacific steelhead (Oncorhynchus mykiss) exposed to chlorpyrifos: benchmark concentration estimates for acetylcholinesterase inhibition. Environmental Toxicology and Chemistry 21:2452-2458.

Scheuerell, M. D., R. Hilborn, M. H. Ruckelshaus, K. K. Bartz, K. M. Lagueux, A. D. Haas, and K. Rawson. 2006. The Shiraz model: a tool for incorporating anthropogenic effects and fish-habitat relationships in conservation planning. Canadian Journal of Fisheries and Aquatic Sciences 63: 1596-1607.

Scholz, N. L., N. K. Truelove, B. L. French, B. A. Berejikian, T. P. Quinn, E. Casillas, and T. K. Collier. 2000. Diazinon disrupts antipredator and homing behaviors in chinook salmon (Oncorhynchus tshawytscha). Canadian Journal of Fisheries and Aquatic Science 57:1911-1918.

Scholz, N. L., N. K. Truelove, J. S. Labenia, D. H. Baldwin, and T. K. Collier. 2006. Dose-additive inhibition of chinook salmon acetylcholinesterase activity by mixtures of organophosphate and carbamate insecticides. Environmental Toxicology and Chemistry 25:1200-1207.

Spromberg, J. A., and J. P. Meador. 2005. Population-level effects on chinook salmon from chronic toxicity test measurement endpoints. Integrated Environmental Assessment and Management 1:9-21.

Van den Brink, P. J., R. P. A. van Wijngaarden, W. G. H. Lucassen, T. C. M. Brock, and P. Leeuwangh. 1996. Effects of the insecticide Dursban 4E (active ingredient chlorpyrifos) in outdoor experimental ditches: II. invertebrate community responses and recovery. Environmental Toxicology and Chemistry 15:1143-1153.

Weatherley, A. H., and H. S. Gill. 1995. Growth. Pages 103158 in C. Groot, L. Margolis, and W. C. Clarke, editors. Physiological ecology of Pacific salmon. University of British Columbia Press, Vancouver, British Columbia, Canada.

Werner, I., L. A. Deanovic, V. Connor, V. De Vlaming, H. C. Bailey, and D. E. Hinton. 2000. Insecticide-caused toxicity to Ceriodaphnia dubia (Cladocera) in the Sacramento-San Joaquin River Delta, California, USA. Environmental Toxicology and Chemistry 19:215-227.

West, C. J., and P. A. Larkin. 1987. Evidence of size-selective mortality of juvenile sockeye salmon (Oncorhynchus nerka) in Babine Lake, British Columbia. Canadian Journal of Fisheries and Aquatic Sciences 44:712-721.

Zabel, R. W., and S. Achord. 2004. Relating size of juveniles to survival within and among populations of chinook salmon. Ecology 85:795-806. 